\title{
Effect of oral antiviral treatment on long-term outcomes of radiofrequency ablation therapy for hepatitis $B$ virus-related hepatocellular carcinoma
}

\author{
Won Sohn ${ }^{1,2, *}$, Tae Wook Kang ${ }^{3, *}$, Sun-Kyu Choi ${ }^{4}$, Sin-Ho Jung ${ }^{4}$, Min Woo Lee ${ }^{3}$, \\ Hyo Keun Lim ${ }^{3,5}$, Ju-Yeon Cho ${ }^{1,6}$, Sang Goon Shim ${ }^{7}$, Dong Hyun Sinn ${ }^{1}$, Geum-Youn \\ Gwak $^{1}$, Moon Seok Choi ${ }^{1}$, Joon Hyeok Lee ${ }^{1}$, Kwang Cheol Koh ${ }^{1}$, Seung Woon Paik ${ }^{1}$, \\ Hyunchul Rhim ${ }^{3, \#}$, Yong-Han Paik ${ }^{1,5, \#}$ \\ ${ }^{1}$ Department of Medicine, Samsung Medical Center, Sungkyunkwan University School of Medicine, Seoul, Korea \\ ${ }^{2}$ Department of Hepatology, Bundang Jesaeng Hospital, Sungnam, Korea \\ ${ }^{3}$ Department of Radiology, Samsung Medical Center, Sungkyunkwan University School of Medicine, Seoul, Korea \\ ${ }^{4}$ Department of Biostatistics and Clinical Epidemiology, Samsung Medical Center, Seoul, Korea \\ ${ }^{5}$ Department of Health Science and Technology, Samsung Advanced Institute for Health Science and Technology, \\ Sungkyunkwan University, Seoul, Korea \\ ${ }^{6}$ Department of Medicine, Chosun University Hospital, Gwang-Ju, Korea \\ ${ }^{7}$ Department of Medicine, Samsung Changwon Hospital, Sungkyunkwan University School of Medicine, Changwon, Korea \\ *These authors have contributed equally to this work \\ \#These authors share senior authorship \\ Correspondence to: Yong-Han Paik, email: yh.paik@skku.edu \\ Keywords: hepatocellular carcinoma, radiofrequency ablation, chronic hepatitis $B$, antiviral treatment \\ Received: January 08, $2016 \quad$ Accepted: May 28, $2016 \quad$ Published: June 14, 2016
}

\section{ABSTRACT}

Objectives: This study aimed to investigate the effect of oral antiviral treatment on the prognosis of hepatitis B virus (HBV)-related hepatocellular carcinoma (HCC) after radiofrequency (RF) ablation.

Methods: Between January 2003 and December 2010, 228 patients without a history of antiviral treatment were treated with RF ablation for a single HBV-related HCC. We divided the patients into two groups, patients who received $(n=125)$ or did not receive antiviral treatment $(n=103)$, based on whether oral antiviral treatment was administered after RF ablation. The median duration of antiviral treatment was 60.1 months. HCC recurrence and overall survival were compared in the two groups in the full cohort and the propensity score-matched cohort.

Results: In the matched cohort, the probability of HCC recurrence at 5 years was $\mathbf{4 3 . 8} \%$ for the non-antiviral treatment group and $14.7 \%$ for the antiviral treatment group $(p<0.001)$. The probability of overall survival at 5 years was $77.2 \%$ for the non-antiviral treatment group and $93.5 \%$ for the antiviral treatment group $(p=0.002)$. Multivariable analysis showed that risk factors for HCC recurrence included large tumor size (hazard ratio $(H R)=1.30, p=0.022)$, HBV DNA serum level $(H R=1.11$, $p=0.005)$, and serum AFP level $\geq 20 \mathrm{ng} / \mathrm{mL}(\mathrm{HR}=1.66, p=0.005)$. Overall survival was associated with larger tumor size $(H R=1.86, p=0.001)$ and Child-Pugh Class $B(H R=2.13, p=0.019)$. Oral antiviral treatment after $R F$ ablation was significantly associated with a lower risk of tumor recurrence and death $(H R=0.33, p<0.001$, and HR=0.44, $p=0.004$ ).

Conclusion: Use of oral antiviral treatment after curative RF ablation was associated with favorable outcomes in terms of tumor recurrence and overall survival in patients with HBV-related HCC. 


\section{INTRODUCTION}

Hepatocellular carcinoma (HCC) is one of the most common cancers [1]. The preferred means of treatment is to detect the tumor at an early stage and to treat with a curative therapy, such as surgical resection, liver transplantation and local ablation [2]. Radiofrequency (RF) ablation is a representative local ablation therapy for HCC treatment. It is widely used to treat $\mathrm{HCC}$ at an early stage when the case is not a candidate for surgical therapies. Currently, RF ablation is recommended as a curative therapeutic modality for patients with very-early stage $\mathrm{HCC}$ according to the recently published Barcelona Clinic Liver Cancer treatment strategy [3].

The therapeutic outcomes of RF ablation for HCC are known to be associated with technical issues (e.g. incomplete ablation), tumor characteristics (e.g. tumor size, number, and location), and underlying liver status (e.g. cirrhosis and hepatic iron accumulation) [4-7]. Recent studies, including that carried out by our group, show that hepatitis viral load is an independent risk factor for prognosis of HCC after surgical resection or $\mathrm{RF}$ ablation in patients with chronic hepatitis $\mathrm{B}$ (CHB) [8-11]. High viral load at resection is associated with tumor recurrence of hepatitis B virus (HBV)-related HCC after resection [8-10]. In addition, our group reported that a high level of HBV DNA at RF ablation is a risk factor for tumor recurrence in HBV-related HCC after RF ablation [11]. Therefore, the control of viral replication may be important for prognosis after the treatment of HBV-related HCC. Recent studies demonstrate that oral antiviral treatment using nucleos(t)ide (nucleoside/ nucleotide) analog results in favorable outcomes in terms of tumor recurrence and overall survival of HBV-related HCC after surgical resection [12-14]. However, a few studies have been carried out to explore on the effect of antiviral treatment on the prognosis of HBV-related HCC after curative RF ablation [15, 16]. Our group reported that the absence of antiviral therapy during follow up was associated with poor survival in HCC patients who received RF ablation as first-line therapy [15]. Recently, Taiwanese investigators reported that nucleos(t)ide analog treatment is associated with a decreased risk of HCC recurrence using nationwide health insurance database [16]. However, previous studies did not provide detailed HBV-related data such as pretreatment HBV DNA levels or $\mathrm{HBeAg}$ status that are known as important factors affecting prognosis in HBV-related HCC. Therefore we aimed to investigate the precise role of nucleos(t)ide analog treatment on the long-term prognosis of HBVrelated HCC after curative RF ablation.

We compared long-term prognosis including tumor recurrence and overall survival between an oral nucleos(t) ide treatment group and a non-treatment group in HBVrelated $\mathrm{HCC}$ after curative RF ablation. In addition, risk factors for tumor recurrence and overall survival of HBVrelated HCC after RF ablation were analyzed.

\section{RESULTS}

\section{Baseline characteristics}

Baseline characteristics of the two groups are described in Table 1. While 103 patients did not receive antiviral treatment after RF ablation, 125 patients received antiviral treatment after RF ablation (entecavir $0.5 \mathrm{mg} / \mathrm{d}$, $\mathrm{n}=68$; lamivudine $100 \mathrm{mg} / \mathrm{d}, \mathrm{n}=45$; clevudine $30 \mathrm{mg} / \mathrm{d}$, $\mathrm{n}=7$; adefovir $10 \mathrm{mg} / \mathrm{d}, \mathrm{n}=4$; tenofovir $300 \mathrm{mg} / \mathrm{d}, \mathrm{n}=1$ ). Supplemental Table 1 shows the stratified characteristics according to antiviral agents. There was no adverse event in patients treated with entecavir, lamivudine, and tenofovir. Mild renal insufficiency occurred in one patient treated with adefovir that was recovered after reducing to half dose. A patient experienced myopathy during clevudine use and was fully recovered after changing to entecavir. The initiation of antiviral treatment was decided according to the KASL guideline in 117 patients of the 125 patients (94\%). However, the antiviral agents were administered to 8 patients $(6 \%)$ who did not meet the KASL guideline according to a physician's recommendation. The median follow-up duration of the patients was 64.8 (interquartile range: 46.8-90.0) and 68.4 (interquartile range: 53.3-89.7) months in the nonantiviral treatment group and the antiviral treatment group, respectively. There was no significant difference in followup duration between the two groups. The median duration of antiviral treatment was 60.1 (interquartile range, 46.177.9) months. The median interval from RF ablation to the beginning of antiviral treatment was 3.4 (interquartile range, 0-16.5) months. There was no significant difference in age, gender, tumor size, platelet count, PT-INR, liver cirrhosis, and Child-Pugh class status between two groups. However, the antiviral treatment group had significantly higher levels of serum AST, ALT, HBV DNA and AFP than the non-antiviral treatment group $(p=0.002$, $p=0.003, p<0.001$, and $p=0.007$ ). Also, the number of patients with HBeAg positivity was significantly higher in the antiviral treatment group than in the non-antiviral treatment group ( $49 \%$ versus $22 \%, p<0.001$ ). Of the 228 patients, histologic diagnosis for HCC was done in 28 patients $(12.3 \%)$. The differentiation type of HCC was Edmondson-Steiner grade I in 10 patients, grade II in 17 patients, and grade IV in 1 patient.

\section{Tumor recurrence and overall survival according to the use of antiviral treatment}

Among all 228 patients, tumor recurrence and death were observed in $152(66.7 \%)$ and $54(23.7 \%)$ patients, respectively. Table 2 shows the comparison of baseline characteristics between the two groups after propensity 
Table 1: Baseline characteristics of all patients $(n=228)$

\begin{tabular}{|c|c|c|c|}
\hline & $\begin{array}{l}\text { Non-antiviral treatment group } \\
\qquad(\mathrm{n}=103)\end{array}$ & $\begin{array}{l}\text { Antiviral treatment group } \\
\qquad(\mathrm{n}=125)\end{array}$ & P-value \\
\hline Age (years) & $55.2 \pm 8.9$ & $55.0 \pm 8.9$ & 0.856 \\
\hline Gender & & & 0.328 \\
\hline women & $23(22 \%)$ & $35(28 \%)$ & \\
\hline men & $80(78 \%)$ & $90(72 \%)$ & \\
\hline Tumor size $(\mathrm{mm})$ & $2.1 \pm 0.6$ & $2.2 \pm 0.7$ & 0.464 \\
\hline Platelet $\left(\times 10^{3} / \mathrm{mm}^{3}\right)$ & $111.9 \pm 48.5$ & $110.2 \pm 45.7$ & 0.792 \\
\hline Prothrombin time (INR) & $1.21 \pm 0.14$ & $1.23 \pm 0.16$ & 0.347 \\
\hline Albumin $(\mathrm{g} / \mathrm{dL})$ & $3.6 \pm 0.5$ & $3.6 \pm 0.6$ & 0.557 \\
\hline Total bilirubin (mg/dL) & $1.0 \pm 0.6$ & $1.0 \pm 0.6$ & 0.721 \\
\hline AST (U/L) & $43.1 \pm 21.9$ & $54.2 \pm 31.8$ & 0.002 \\
\hline ALT (U/L) & $36.9 \pm 32.3$ & $52.1 \pm 42.5$ & 0.003 \\
\hline $\log _{10} \mathrm{HBV}$ DNA ( IU/mL) & $2.8 \pm 2.6$ & $5.3 \pm 2.0$ & $<0.001$ \\
\hline $\operatorname{AFP}(n g / m L)$ & & & 0.007 \\
\hline$<20$ & $57(55 \%)$ & $47(38 \%)$ & \\
\hline$\geq 20$ & $46(45 \%)$ & $78(62 \%)$ & \\
\hline $\operatorname{HBeAg}(\mathrm{N}, \%)$ & & & $<0.001$ \\
\hline negative & $80(78 \%)$ & $64(51 \%)$ & \\
\hline positive & $23(22 \%)$ & $61(49 \%)$ & \\
\hline \multicolumn{4}{|l|}{ Liver cirrhosis $(\mathrm{N}, \%)$} \\
\hline absence & $17(17 \%)$ & $21(17 \%)$ & 0.953 \\
\hline presence & $86(83 \%)$ & $104(83 \%)$ & \\
\hline Child-Pugh class $(\mathrm{N}, \%)$ & & & 0.661 \\
\hline $\mathrm{A}$ & $86(83 \%)$ & $107(86 \%)$ & \\
\hline B & $17(17 \%)$ & $18(14 \%)$ & \\
\hline \multicolumn{4}{|l|}{ Antiviral therapy $(\mathrm{N}, \%)$} \\
\hline Lamivudine & & $68(54 \%)$ & \\
\hline Entecavir & & $45(36 \%)$ & \\
\hline Clevudine & & $7(6 \%)$ & \\
\hline Adefovir & & $4(3 \%)$ & \\
\hline Tenofovir & & $1(1 \%)$ & \\
\hline
\end{tabular}

Data are presented as the mean \pm standard deviation or number of patients (percentages in parentheses).

*Abbreviations: RF, radiofrequency; INR, international normalized ratio; AST, aspartate aminotransferase; ALT, alanine aminotransferase; HBV, hepatitis B virus; AFP, alpha-fetoprotein; HBeAg, hepatitis B envelope antigen.

score matching. After matching, 104 patients were included in the antiviral treatment group and 62 patients were included in the non-antiviral treatment group. There was no significant difference in all clinical variables including serum AST, ALT, HBV DNA, AFP, and HBeAg status between the two groups. In addition, the mean standardized difference of each variable indicated very small differences between the groups.

We compared the differences in time to recurrence and overall survival according to the use of antiviral treatment after RF ablation in both the full and matched cohorts (Figure 1). In the full cohort, the probability of 
Table 2: Baseline characteristics of matched patients $(n=166)$

\begin{tabular}{|c|c|c|c|c|}
\hline & $\begin{array}{l}\text { Non-antiviral treatment group } \\
\qquad(\mathrm{n}=62)\end{array}$ & $\begin{array}{l}\text { Antiviral treatment group } \\
\qquad(\mathrm{n}=104)\end{array}$ & P-value & $\begin{array}{l}\text { Standardized } \\
\text { mean difference }\end{array}$ \\
\hline Age (years) & $55.6 \pm 9.0$ & $55.5 \pm 9.2$ & 0.939 & 0.012 \\
\hline Gender & & & 0.721 & 0.063 \\
\hline women & $20(32 \%)$ & $31(30 \%)$ & & \\
\hline men & $42(68 \%)$ & $73(70 \%)$ & & \\
\hline Tumor size $(\mathrm{cm})$ & $2.3 \pm 0.6$ & $2.2 \pm 0.7$ & 0.715 & 0.065 \\
\hline Platelet $\left(\mathrm{x} 10^{3} / \mathrm{mm}^{3}\right)$ & $112.3 \pm 47.3$ & $111.4 \pm 45.0$ & 0.903 & 0.019 \\
\hline Prothrombin time (INR) & $1.22 \pm 0.15$ & $1.22 \pm 0.16$ & 0.949 & -0.011 \\
\hline Albumin (g/dL) & $3.6 \pm 0.4$ & $3.6 \pm 0.6$ & 0.874 & 0.025 \\
\hline Total bilirubin (mg/dL) & $1.0 \pm 0.7$ & $1.0 \pm 0.6$ & 0.876 & 0.025 \\
\hline $\operatorname{AST}(\mathrm{U} / \mathrm{L})$ & $46.9 \pm 25.1$ & $47.7 \pm 22.3$ & 0.828 & -0.039 \\
\hline $\operatorname{ALT}(\mathrm{U} / \mathrm{L})$ & $42.2 \pm 39.2$ & $42.4 \pm 21.9$ & 0.958 & -0.009 \\
\hline $\log _{10} \mathrm{HBV}$ DNA ( IU/mL) & $4.2 \pm 2.5$ & $4.4 \pm 2.2$ & 0.504 & -0.091 \\
\hline $\mathrm{AFP}(\mathrm{ng} / \mathrm{mL})$ & & & 0.930 & 0.013 \\
\hline$<20$ & $28(45 \%)$ & $48(46 \%)$ & & \\
\hline$\geq 20$ & $34(55 \%)$ & $56(54 \%)$ & & \\
\hline $\operatorname{HBeAg}(\mathrm{N}, \%)$ & & & 0.910 & -0.021 \\
\hline negative & $41(66 \%)$ & $68(65 \%)$ & & \\
\hline positive & $21(34 \%)$ & $36(35 \%)$ & & \\
\hline Liver cirrhosis $(\mathrm{N}, \%)$ & & & 0.737 & 0.048 \\
\hline absence & $7(11 \%)$ & $14(13 \%)$ & & \\
\hline presence & $55(89 \%)$ & $90(87 \%)$ & & \\
\hline Child-Pugh class (N, \%) & & & 0.971 & 0.006 \\
\hline A & $52(84 \%)$ & $87(84 \%)$ & & \\
\hline B & $10(16 \%)$ & $17(16 \%)$ & & \\
\hline
\end{tabular}

*Abbreviations: RF, radiofrequency; INR, international normalized ratio; AST, aspartate aminotransferase; ALT, alanine aminotransferase; HBV, hepatitis B virus; AFP, alpha-fetoprotein; HBeAg, hepatitis B envelope antigen.

1-year, 3-year, 5-year, and 10-year recurrence were $18.4 \%$, $64.7 \%, 77.3 \%$, and $100 \%$, respectively, in the non-antiviral treatment group; and $10.4 \%, 35.9 \%, 56.1 \%$, and $78.2 \%$, respectively, in the antiviral treatment group (Figure 1A). The median time to recurrence was 1.9 (95\% CI: 1.4-2.4) and 4.0 (95\% CI: 3.3-4.7) years in the non-antiviral and antiviral treatment groups, respectively. Tumor recurrence was significantly different between the two groups $(p<0.001)$. The probabilities of 1-year, 3-year, 5-year, and 10 -year overall survival were $100 \%, 90.3 \%, 82.3 \%$, and $60.3 \%$, respectively, in the non-antiviral treatment group, and $100 \%, 96.8 \%, 90.5 \%$, and $75.7 \%$, respectively, in the antiviral treatment group (Figure 1B). The mean duration of overall survival was 8.9 (95\% CI: 8.1-9.7) and 9.7 (95\% CI: 9.1-10.3) years in the non-antiviral and antiviral treatment groups, respectively. Overall survival was significantly different between the two groups $(p=0.008)$.

In the matched cohort, the probabilities of 1-year, 3 -year, 5-year, and 10-year recurrence were 27.4\%, 71.8\%, $85.3 \%$, and $100 \%$, respectively, in the non-antiviral treatment group, and $8.7 \%, 32.8 \%, 56.2 \%$, and $77.7 \%$, respectively, in the antiviral treatment group (Figure 1C). The median time to recurrence was 1.6 (95\% CI: 1.2-2.7) and 4.0 (95\% CI: 3.6-6.8) years in the non-antiviral and 
antiviral treatment groups, respectively. Tumor recurrence was significantly different between the two groups $(p<0.001)$. The probabilities of 1-year, 3-year, 5-year, and 10 -year overall survival were $100 \%, 87.1 \%, 77.2 \%$, and $52.4 \%$, respectively, in the non-antiviral treatment group; and $100 \%, 97.5 \%, 93.5 \%$, and $82.1 \%$, respectively, in the antiviral treatment group (Figure 1D). The mean duration of overall survival was 6.1 (95\% CI: 5.6-6.7) and 9.4 (95\% CI: 8.9-9.9) years in the non-antiviral and antiviral treatment groups, respectively. Overall survival was significantly different between the two groups $(p=0.002)$.

The recurrence events and therapeutic modalities until the end of the follow-up were demonstrated in Supplementary Figure 1 and Supplementary Table 2. Also, we checked the percentage of complete ablation in each event. The complete ablation rates were $95.9 \%(71 / 74)$ at the 1 st event, $96.9 \%(31 / 32)$ at the 2 nd event, and $100 \%$ $(9 / 9)$ at the 3 rd event.
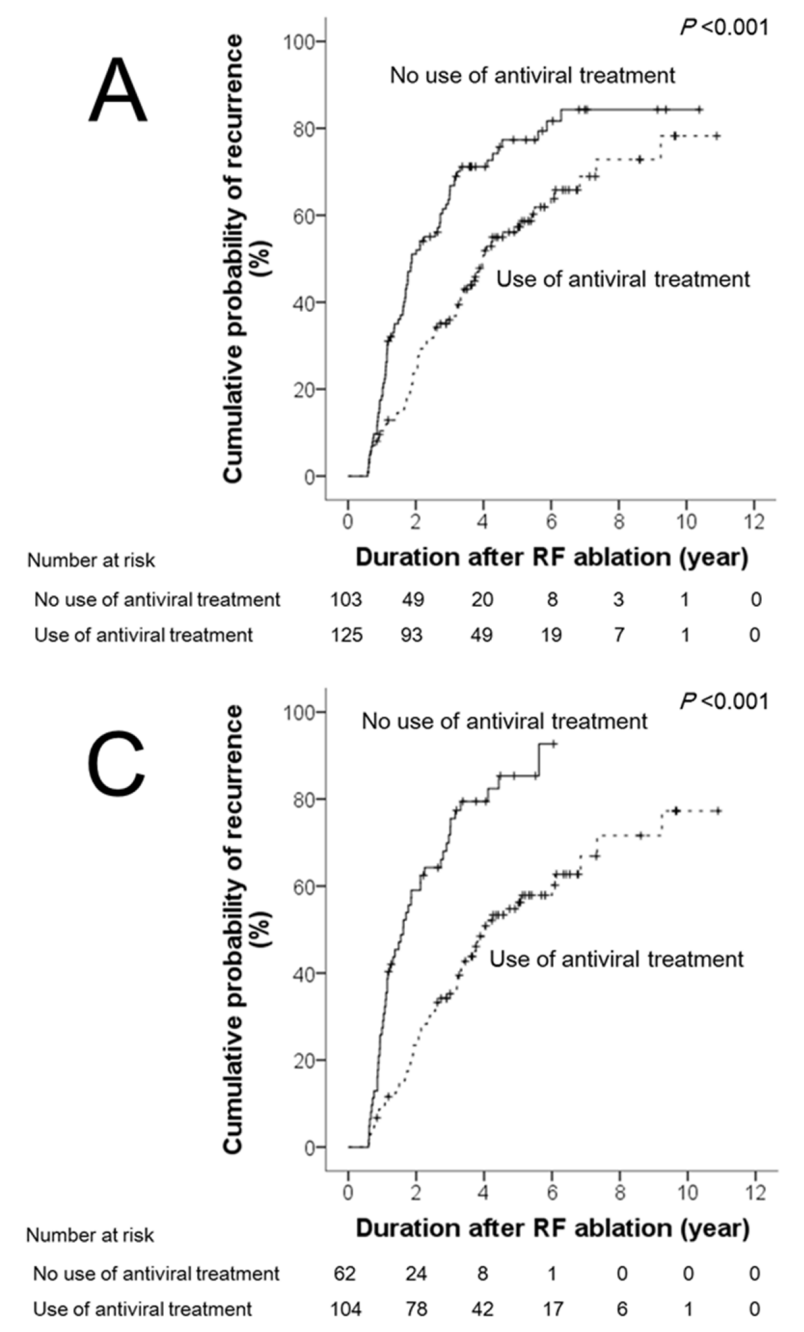

\section{Risk factors for tumor recurrence}

Table 3 shows the risk factors for tumor recurrence of HBV-related HCC after RF ablation in the full cohort. Univariable analysis revealed that tumor recurrence was significantly associated with larger tumor size (hazard ratio $(\mathrm{HR})=1.35(95 \% \mathrm{CI}: 1.08-1.68), p=0.008)$, increased PT-INR (HR=3.18 (95\% CI: 1.27-7.95), $p=0.013)$, a lower level of serum albumin $(\mathrm{HR}=0.65$ (95\% CI: $0.49-0.87)$, $p=0.003)$, and serum AFP level $\geq 20 \mathrm{ng} / \mathrm{mL}(\mathrm{HR}=1.53$ (95\% CI: 1.11-2.12), $p=0.009)$. In addition, the use of antiviral treatment after RF ablation was associated with a significantly lower risk of tumor recurrence $(\mathrm{HR}=0.53$ (95\% CI: 0.38-0.73), $p<0.001)$. Multivariable analysis revealed that tumor recurrence was associated with larger tumor size $(\mathrm{HR}=1.30$ (95\% CI: 1.04-1.63), $p=0.022)$, higher serum HBV DNA level (HR=1.11 (95\% CI: $1.03-1.20), p=0.005)$, and serum AFP level $\geq 20 \mathrm{ng} /$
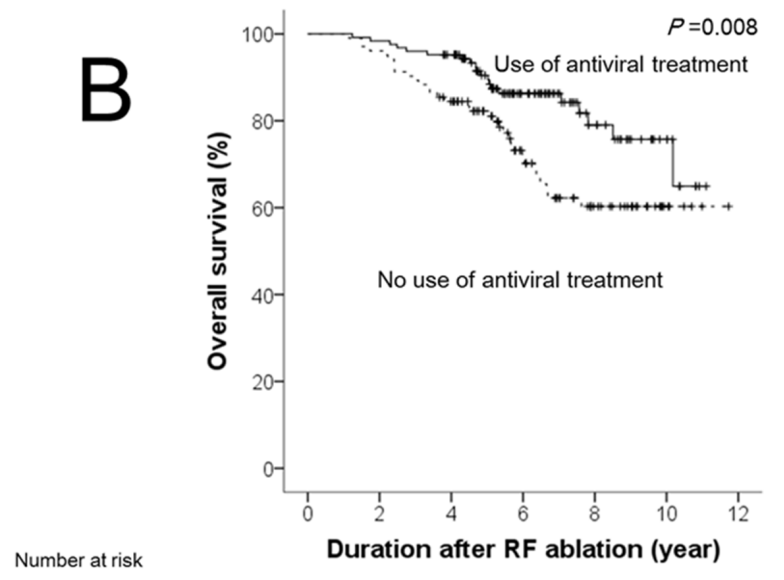

$\begin{array}{lccccccc}\text { Use of antiviral treatment } & 125 & 123 & 115 & 61 & 27 & 10 & 0 \\ \text { No use of antiviral treatment } & 103 & 99 & 84 & 48 & 25 & 6 & 0\end{array}$

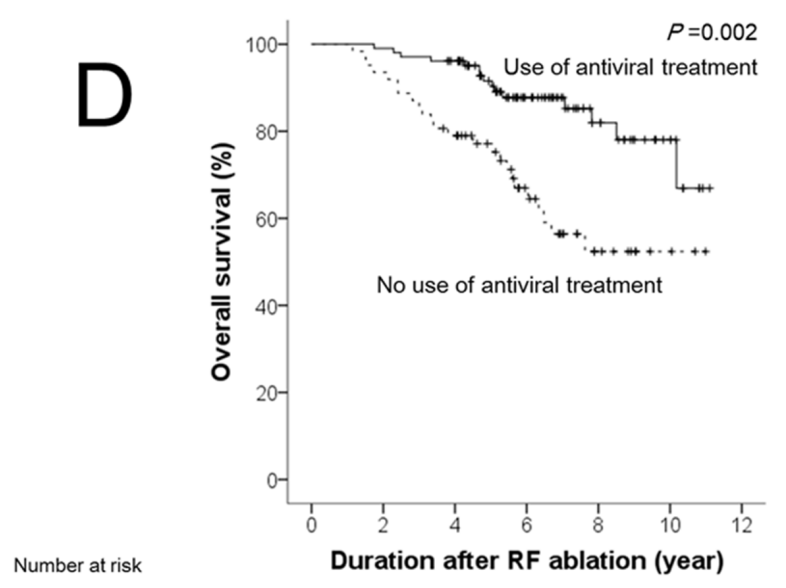

$\begin{array}{lllllllll}\text { Use of antiviral treatment } & 104 & 103 & 97 & 51 & 23 & 10 & 0\end{array}$ $\begin{array}{llllllll}\text { No use of antiviral treatment } & 62 & 58 & 48 & 27 & 10 & 3 & 0\end{array}$

Figure 1: Differences in time to recurrence and overall survival according to the use of antiviral treatment after RF ablation in the full cohort $A \&$ B. and the matched cohort $\mathbf{C} \& \mathbf{D}$.

*Abbreviation: RF, radiofrequency. 
Table 3: Univariable and multivariable analyses of risk factors for recurrence of $\mathrm{HBV}$-related $\mathrm{HCC}$ patients after RF ablation in the full cohort $(n=228)$

\begin{tabular}{|c|c|c|c|c|}
\hline & $\begin{array}{c}\text { Univariable HR } \\
(95 \% \mathrm{CI})\end{array}$ & $p$-value & $\begin{array}{c}\text { Multivariable HR } \\
(95 \% \text { CI })\end{array}$ & $p$-value \\
\hline Age (years) & $1.00(0.97-1.01)$ & 0.547 & & \\
\hline Men & $0.98(0.68-1.40)$ & 0.908 & & \\
\hline Tumor size (mm) & $1.35(1.08-1.68)$ & 0.008 & $1.30(1.04-1.63)$ & 0.022 \\
\hline Platelet $\left(\mathrm{x} 10^{3} / \mathrm{mm}^{3}\right)$ & $1.00(0.99-1.00)$ & 0.151 & & \\
\hline Prothrombin time (INR) & $3.18(1.27-7.95)$ & 0.013 & & \\
\hline Albumin (g/dL) & $0.65(0.49-0.87)$ & 0.003 & & \\
\hline Total bilirubin (mg/dL) & $1.21(0.97-1.50)$ & 0.092 & & \\
\hline $\operatorname{AST}(\mathrm{U} / \mathrm{L})$ & $1.00(0.99-1.01)$ & 0.142 & & \\
\hline $\operatorname{ALT}(\mathrm{U} / \mathrm{L})$ & $1.00(0.99-1.01)$ & 0.793 & & \\
\hline $\log _{10} \mathrm{HBV}$ DNA ( IU/mL) & $1.05(0.98-1.11)$ & 0.171 & $1.11(1.03-1.20)$ & 0.005 \\
\hline $\operatorname{AFP}(\geq 20 \mathrm{ng} / \mathrm{mL})$ & $1.53(1.11-2.12)$ & 0.009 & $1.66(1.17-2.36)$ & 0.005 \\
\hline $\operatorname{HBeAg}(+)$ & $1.32(0.95-1.83)$ & 0.094 & & \\
\hline Liver cirrhosis $(+)$ & $1.34(0.85-2.11)$ & 0.205 & & \\
\hline Child-Pugh class B & $1.43(0.94-2.18)$ & 0.099 & & \\
\hline Antiviral treatment after RF ablation $(+)$ & $0.53(0.38-0.73)$ & $<0.001$ & $0.33(0.23-0.48)$ & $<0.001$ \\
\hline
\end{tabular}

*Abbreviations: HBV, hepatitis B virus; HCC, hepatocellular carcinoma; RF, radiofrequency; HR, hazard ratio; CI, confidence interval; INR, international normalized ratio; AST, aspartate aminotransferase; ALT, alanine aminotransferase; AFP, alpha-fetoprotein; HBeAg, hepatitis B envelope antigen.

$\mathrm{mL}(\mathrm{HR}=1.66(95 \% \mathrm{CI}: 1.17-2.36), p=0.005)$. Use of antiviral treatment after RF ablation was also significantly associated with lower risk of tumor recurrence $(\mathrm{HR}=0.33$, (95\% CI: 0.23-0.48), $p<0.001)$.

In a subgroup analysis based on tumor size, multivariable analysis showed that use of antiviral treatment after RF ablation was associated with a significantly lower risk of tumor recurrence $(\mathrm{HR}=0.41$ (95\% CI: 0.24-0.69), $p=0.001$ ) in patients with tumor size $<2 \mathrm{~cm}$. In patients with tumor size $\geq 2 \mathrm{~cm}$, multivariable analysis showed that tumor recurrence was associated with increased PT-INR (HR=8.72 (95\% CI: 2.06-36.91), $p=0.003)$, and serum AFP level $\geq 20 \mathrm{ng} / \mathrm{mL}(\mathrm{HR}=1.83$ (95\% CI: $1.17-2.86), p=0.009)$. The use of antiviral treatment after RF ablation was associated with a significantly lower risk of tumor recurrence $(\mathrm{HR}=0.44$ (95\% CI: 0.28-0.70), $p<0.001$ ) (Table 4).

Table 5 demonstrates the risk factors for tumor recurrence of $\mathrm{HBV}$-related $\mathrm{HCC}$ after $\mathrm{RF}$ ablation in sub-analysis based on hepatitis B viral load (HBV DNA levels $\geq 2,000 \mathrm{IU} / \mathrm{mL}$ or $<2,000 \mathrm{IU} / \mathrm{mL}$ ). The use of antiviral treatment after RF ablation was associated with a significantly lower risk of tumor recurrence in patients with a low viral load (HBV DNA $<2,000 \mathrm{IU} / \mathrm{mL}$ ) $(\mathrm{HR}=0.28(95 \% \mathrm{CI}: 0.13-0.63), p=0.002)$ as well as in those with a high viral load (HBV DNA $\geq 2,000 \mathrm{IU} / \mathrm{mL}$ ) $(\mathrm{HR}=0.32(95 \% \mathrm{CI}: 0.21-0.50), p<0.001)$.

\section{Risk factors for overall survival}

Table 6 demonstrates the risk factors for overall survival of patients with HBV-related HCC after RF ablation in the full cohort. Univariable analysis showed that unfavorable overall survival was significantly associated with larger tumor size $(\mathrm{HR}=1.65$ (95\% CI: 1.16$2.33), p=0.005)$, lower serum albumin level $(\mathrm{HR}=0.56$ (95\% CI: 0.34-0.93), $p=0.025)$, higher serum AST level $(\mathrm{HR}=1.01$ (95\% CI: 1.00-1.02), $p=0.039)$, and Child-Pugh Class B (HR=1.94 (95\% CI: 1.04-3.63), $p=0.038)$. The use of antiviral treatment after RF ablation had a significantly favorable effect on overall survival $(\mathrm{HR}=0.48$ (95\% CI: $0.28-0.84), p=0.010)$. Multivariable analysis revealed that unfavorable overall survival was associated with larger tumor size $(\mathrm{HR}=1.86$ (95\% CI: 1.28-2.70), $p=0.001)$ and Child-Pugh Class B (HR=2.13 (95\% CI: 1.13-4.00), 
Table 4: Multivariable analysis of risk factors for tumor recurrence of $\mathrm{HBV}$-related $\mathrm{HCC}$ after RF ablation in a subgroup of patients according to tumor size

\begin{tabular}{|c|c|c|c|c|}
\hline & \multicolumn{2}{|c|}{ Tumor size $<2 \mathrm{~cm}$} & \multicolumn{2}{|c|}{ Tumor size $\geq 2 \mathrm{~cm}$} \\
\hline & HR $(95 \%$ CI $)$ & $p$-value & HR $(95 \%$ CI $)$ & $p$-value \\
\hline Prothrombin time (INR) & & & $8.72(2.06-36.91)$ & 0.003 \\
\hline $\operatorname{AFP}(\geq 20 \mathrm{ng} / \mathrm{mL})$ & & & $1.83(1.17-2.86)$ & 0.009 \\
\hline Antiviral treatment after RF ablation $(+)$ & $0.41(0.24-0.69)$ & 0.001 & $0.44(0.28-0.70)$ & $<0.001$ \\
\hline
\end{tabular}

*Abbreviations: HBV, hepatitis B virus; HCC, hepatocellular carcinoma; RF, radiofrequency; HR, hazard ratio; CI, confidence interval; INR, international normalized ratio; AFP, alpha-fetoprotein.

Table 5: Multivariable analysis of risk factors for tumor recurrence of $\mathrm{HBV}$-related $\mathrm{HCC}$ after RF ablation in a subgroup of patients according to hepatitis $B$ viral load

\begin{tabular}{|c|c|c|c|c|}
\hline & \multicolumn{2}{|c|}{ HBV DNA $<2,000 \mathrm{IU} / \mathrm{mL}$} & \multicolumn{2}{|c|}{ HBV DNA $\geq 2,000 \mathrm{IU} / \mathrm{mL}$} \\
\hline & HR $(95 \%$ CI $)$ & $p$-value & HR (95\% CI) & $p$-value \\
\hline Tumor size (mm) & & & $1.30(1.01-1.66)$ & 0.043 \\
\hline Prothrombin time (INR) & $11.53(1.53-87.17)$ & 0.018 & & \\
\hline AST (U/L) & $1.01(1.00-1.03)$ & 0.034 & & \\
\hline $\log _{10} \mathrm{HBV}$ DNA ( IU/mL) & & & $1.30(1.06-1.59)$ & 0.013 \\
\hline $\operatorname{AFP}(\geq 20 \mathrm{ng} / \mathrm{mL})$ & $3.16(1.63-6.13)$ & 0.001 & & \\
\hline Antiviral treatment after RF ablation $(+)$ & $0.28(0.13-0.63)$ & 0.002 & $0.32(0.21-0.50)$ & $<0.001$ \\
\hline
\end{tabular}

*Abbreviations: HBV, hepatitis B virus; HCC, hepatocellular carcinoma; RF, radiofrequency; HR, hazard ratio; CI, confidence interval; INR, international normalized ratio; AST, aspartate aminotransferase ; AFP, alpha-fetoprotein.

$p=0.019)$. The use of antiviral treatment after RF ablation was significantly associated with favorable overall survival $(\mathrm{HR}=0.44,(95 \% \mathrm{CI}: 0.25-0.77), p=0.004)$.

\section{DISCUSSION}

Chronic viral hepatitis is the most common cause of HCC [28]. High HBV load is associated with a poor prognosis in patients treated for HBV-related HCC $[9,29]$. Multiple lines of evidence indicate that use of oral antiviral treatment improves clinical outcomes in patients with chronic hepatitis B. Liaw et al. showed that lamivudine treatment delays disease progression and reduces the incidence of $\mathrm{HCC}$ in patients with chronic hepatitis B [30]. Hosaka et al. reported that long-term use of entecavir decreases the incidence of HCC in chronic hepatitis B patients [31]. Also, a significant improvement of hepatic fibrosis or cirrhosis was demonstrated in CHB patients who received oral antiviral treatment $[32,33]$.

Thus, previous studies provided a rationale for suppressing viral replication using antiviral treatment to improve the prognosis of HBV-related HCC patients following curative therapy. The use of oral antiviral treatment was shown to be associated with a lower risk of tumor recurrence and increased overall survival in patients with $\mathrm{HBV}$-related $\mathrm{HCC}$ that underwent surgical resection $[12,13]$. However, there are a few studies about the effect of oral antiviral treatment on the prognosis of HBV-related HCC patients after RF ablation.

In this study, we investigated long-term clinical outcomes of tumor recurrence and overall survival after RF ablation in HBV-related HCC according to the use of antiviral treatment after ablation. Previous studies reported that the following risk factors are associated with prognosis in HCC patients after RF ablation: age, cirrhosis, Child-Pugh class, tumor size, tumor number, serum tumor marker, and extrahepatic recurrences [15, $16,34]$. Our study showed that several baseline factors were associated with HCC recurrence and overall survival after RF ablation: serum AST, ALT, HBV DNA, AFP, and the presence of $\mathrm{HBeAg}$ in full cohort. To minimize the effect of risk factors other than antiviral treatment between the two groups, we analyzed the data using propensity score matching. After matching, there was no significant difference in risk factors between the two groups and analysis using matched cohorts indicated that overall survival is associated with Child-Pugh class, tumor size, and antiviral therapy. The results of our study indicate a clear beneficial effect of oral antiviral treatment on 
Table 6: Univariable and multivariable analyses of risk factors for overall survival of HBV-related HCC patients after RF ablation in the full cohort $(n=228)$

\begin{tabular}{|c|c|c|c|c|}
\hline & $\begin{array}{c}\text { Univariable HR } \\
(95 \% \mathrm{CI})\end{array}$ & $p$-value & $\begin{array}{c}\text { Multivariable HR } \\
(95 \% \text { CI })\end{array}$ & $p$-value \\
\hline Age (years) & $0.99(0.96-1.02)$ & 0.621 & & \\
\hline Men & $0.98(0.68-1.40)$ & 0.439 & & \\
\hline Tumor size (mm) & $1.65(1.16-2.33)$ & 0.005 & $1.86(1.28-2.70)$ & 0.001 \\
\hline Platelet $\left(\mathrm{x} 10^{3} / \mathrm{mm}^{3}\right)$ & $1.00(0.99-1.00)$ & 0.130 & & \\
\hline Prothrombin time (INR) & $3.05(0.65-14.24)$ & 0.156 & & \\
\hline Albumin (g/dL) & $0.56(0.34-0.93)$ & 0.025 & & \\
\hline Total bilirubin $(\mathrm{mg} / \mathrm{dL})$ & $1.23(0.87-1.75)$ & 0.236 & & \\
\hline $\operatorname{AST}(\mathrm{U} / \mathrm{L})$ & $1.01(1.00-1.02)$ & 0.039 & & \\
\hline $\operatorname{ALT}(\mathrm{U} / \mathrm{L})$ & $1.00(1.00-1.01)$ & 0.247 & & \\
\hline $\log _{10} \mathrm{HBV}$ DNA ( IU/mL) & $1.03(0.93-1.14)$ & 0.561 & & \\
\hline $\operatorname{AFP}(\geq 20 \mathrm{ng} / \mathrm{mL})$ & $0.90(0.53-1.55)$ & 0.706 & & \\
\hline $\operatorname{HBeAg}(+)$ & $1.31(0.76-2.26)$ & 0.335 & & \\
\hline Liver cirrhosis $(+)$ & $2.09(0.75-5.80)$ & 0.158 & & \\
\hline Child-Pugh class B & $1.94(1.04-3.63)$ & 0.038 & $2.13(1.13-4.00)$ & 0.019 \\
\hline Antiviral treatment after RF ablation $(+)$ & $0.48(0.28-0.84)$ & 0.010 & $0.44(0.25-0.77)$ & 0.004 \\
\hline
\end{tabular}

*Abbreviations: HBV, hepatitis B virus; HCC, hepatocellular carcinoma; RF, radiofrequency; HR, hazard ratio; CI, confidence interval; INR, international normalized ratio; AST, aspartate aminotransferase; ALT, alanine aminotransferase; AFP, alpha-fetoprotein; HBeAg, hepatitis B envelope antigen.

reducing tumor recurrence and improving overall survival of HBV-related HCC after RF ablation.

To our knowledge, there have been two studies exploring the effect of oral antiviral treatment on the prognosis of HBV-related HCC after RF ablation [15, 16]. Those studies showed that antiviral treatment was associated with reduced tumor recurrence in HCC patients after RF ablation. However, there was still insufficient data regarding the effect of $\mathrm{HBV}$ suppression by oral antiviral therapy on patients' survival after RF ablation therapy. Recently, Taiwanese investigators reported that nucleos $(\mathrm{t})$ ide analog therapy is associated with a decreased risk of HCC recurrence. However, there was statistically no difference in the 3-year overall mortality between oral antiviral treatment group and no treatment group [16]. Because they used nationwide health insurance research database, detailed information of pretreatment HBV viral load or HBeAg status is missing. HBV factors including $\mathrm{HBeAg}$ status and HBV viral load are important known risk factors for clinical outcomes of HBV-related HCC. Our study performed detailed analysis including HBV suppressing effect of oral antiviral treatment in HBVrelated $\mathrm{HCC}$ patients after RF ablation. We found that oral antiviral treatment not only reduces $\mathrm{HCC}$ recurrences but also improves patients' survival after curative RF ablation.
Most clinical guidelines indicate that use of antiviral treatment is recommended in CHB patients with both high HBV DNA level and increased ALT level [35-37]. We analyzed $\mathrm{HCC}$ recurrence according to pretreatment $\mathrm{HBV}$ DNA levels. Interestingly, the use of antiviral treatment after RF ablation was associated with a significantly lower risk of tumor recurrence in patients with a low viral load as well as in those with a high viral load. Based on our results, we think that the use of oral antiviral treatment is recommended for HBV-related HCC patients harboring any grade of HBV replication after RF ablation. Recently, Sinn et al. reported that compensated cirrhotic patients with low viral load (HBV DNA $<2000 \mathrm{IU} / \mathrm{mL}$ ) were not at low risk for $\mathrm{HCC}$, and oral antiviral therapy was associated with lower HCC risk, corroborating our findings [38].

In this study, 19 patients were excluded due to incomplete ablation (3.4\%). These patients were considered as a technical RF ablation failure. The causes of technical failure were as follows; difficult to approach tumor location (i.e. hepatic hilum, gallbladder, and dome area) in 14 patients, heat sink effect (because the tumor was adjacent to a large vessel) in 4 patients, and poor cooperation during the RF ablation procedure in 1 patient. For the accurate analysis, we only included the patients with complete ablation and excluded patients who showed 
a technical RF ablation failure. It is impossible to evaluate whether the antiviral treatment influences HCC recurrence in patients with a technical failure because we cannot regard that those patients received a curative therapy.

Our study has several limitations. First, we conducted the study for the patients with a single HCC with a maximum diameter $<5 \mathrm{~cm}$. Although all guidelines recommend RF ablation in HCC with a single nodule $(<5 \mathrm{~cm})$ or $2-3$ nodules $(<3 \mathrm{~cm})$, multiple nodules is an independent factor for tumor recurrence and overall survival $[2,39]$. In this study, we aimed to evaluate the prognosis of HBV-related HCC cases after RF ablation according to the use of antiviral treatment rather than tumor characteristics. Therefore, we limited our study to patients with a single nodular HCC. Our results could not be directly translated to patients who undergo RF ablation for multiple HCCs since patients with single tumor were solely included in our study. Second, the starting time point of oral antiviral treatment after RF ablation was not consistent because this study was conducted by a retrospective approach using a historical cohort. Third, this study could not analyze the clinical outcomes after RF ablation according to antiviral agent. The followup duration was so different according to antiviral agent because the launch date of each antiviral agent was different in Korea. For example, entecavir was not available in cohort entry date because it was released in 2007 in Korea. Finally, we did not take into account the biological aggressiveness of the tumor because histologic features cannot be obtained in terms of RF ablation therapy, unlike in cases of surgical resection.

In conclusion, the use of oral antiviral treatment was associated with favorable outcomes in terms of tumor recurrence and overall survival in patients with $\mathrm{HBV}$ related HCC after RF ablation therapy.

\section{PATIENTS AND METHODS}

\section{Study design and patients}

This is a retrospective study that uses a historical cohort taken from Samsung Medical Center, Seoul, Korea. From January 2003 to December 2010, 551 patients with CHB were treated with RF ablation as a first-line treatment for a single HCC with a maximum diameter of less than $5 \mathrm{~cm}$ (Figure 2). Our inclusion criteria for RF ablation in patients with $\mathrm{HCC}$ were the same as described in previous studies [15, 17]. Chronic hepatitis B was defined as HBsAg positive for at least 6 months. We excluded the following patients: other concurrent malignancies $(n=8)$; co-infection with hepatitis $\mathrm{C}$ virus $(n=6)$; Child-Pugh class $\mathrm{C}(\mathrm{n}=5)$; incomplete ablation for $\mathrm{HCC}$ at computed tomography (CT) obtained immediately after RF ablation (technical failure of RF ablation) $(\mathrm{n}=19)$; incomplete data on laboratory studies $(n=29)$; HCC recurrence within 6 months of RF ablation ( $\mathrm{n}=28)$; lack of follow-up within
6 months of RF ablation ( $\mathrm{n}=8)$; and liver transplantation without HCC recurrence after RF ablation $(n=1)$. To exclude the potential influence of technical factor for RF ablation procedure on the patient's outcome, the patients with local tumor progression (LTP) during follow up $(n=33)$ were further excluded [18]. In order to evaluate the effect of post-RF ablation antiviral treatment on the prognosis of HBV-related HCC, 186 patients were additionally excluded because of administration of antiviral agent prior to RF ablation. We regarded at least 3 months as a significant duration of antiviral treatment before RF ablation. Finally, we selected $228 \mathrm{HCC}$ patients who were treated using RF ablation for HBV-related $\mathrm{HCC}$. The diagnosis of HCC was done on the basis of American Association for the Study of Liver Diseases (AASLD) guidelines [19]. The indication for the initiation of antiviral treatment was based on Korean Association for the Study of the Liver (KASL) guideline: (i) HBV $\mathrm{DNA} \geq 20,000 \mathrm{IU} / \mathrm{mL}$ and serum aminotransferase level (AST or ALT) $\geq 2$ upper limit of normal (ULN) in patients who were $\mathrm{HBeAg}$ positive; (ii) $\mathrm{HBV} \mathrm{DNA} \geq 2,000 \mathrm{IU} /$ $\mathrm{mL}$ and serum aminotransferase level $\geq 2$ ULN in patients who were $\mathrm{HBeAg}$ negative; and (iii) $\mathrm{HBV}$ DNA $\geq 2,000$ $\mathrm{IU} / \mathrm{mL}$ and serum aminotransferase level above ULN in cirrhotic patients $[20,21]$. This study was approved by the Institutional Review Board of Samsung Medical Center.

\section{Clinical parameters}

We checked the following baseline characteristics at the time of RF ablation therapy: age, sex, tumor size, platelet count, prothrombin time-international normalized ratio (PT-INR), albumin, total bilirubin, aspartate transaminase (AST), alanine transaminase (ALT), alphafetoprotein (AFP), HBV DNA level, presence of HBV envelope antigen (HBeAg), presence of liver cirrhosis, Child-Pugh classification, and use of antiviral treatment after RF ablation. Serum HBV DNA level was measured using a hybrid capture assay (Digene Corporation, Gaithersburg, MD, USA) before 2007. After 2007, the COBAS TaqMan hepatitis B virus quantitative test (Roche Molecular Systems Inc., Branchburg, NJ, USA) was used for HBV DNA level testing. Liver cirrhosis was diagnosed histologically $(n=32)$ or clinically according to laboratory and ultrasonographic (US) findings [22]. The antiviral treatment group after RF ablation was defined as those patients who received antiviral treatment for at least 6 months prior to tumor recurrence.

\section{RF ablation procedure}

Before hospitalization for RF ablation, technical feasibility of RF ablation in all patients was assessed on an outpatient basis with planning US [23]. All RF ablation procedures were performed percutaneously under real-time US guidance with local anesthesia and 
conscious analgesic sedation by M.W.L, H.R. and H.K.L. all of whom had at least 5 years of experience with this procedure prior to the beginning of our study [24]. We used an internally cooled electrode system with generators
(Cool-tip RF System, Covidien, Mansfield, MA; VIVA RF ablation System, STARmed, Ilsan, Korea). Either a single or multiple straight electrodes or a cluster electrode were used depending on tumor size and tumor characteristics.

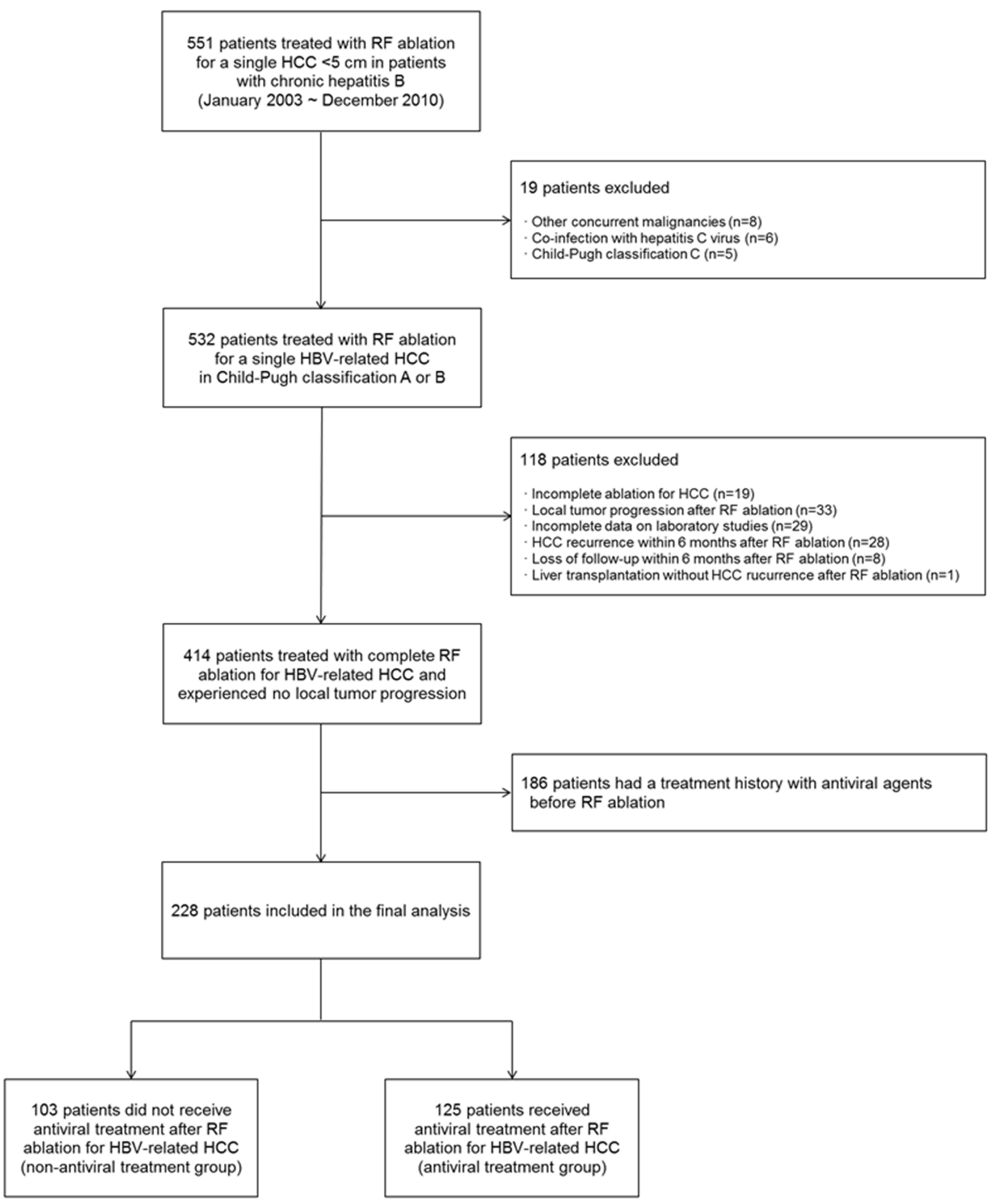

Figure 2: Flow diagram of enrolled patients.

*Abbreviation: RF, radiofrequency; HCC, hepatocellular carcinoma; HBV, hepatitis B virus. 
We followed the manufacturer's recommended protocol as an algorithm for energy deposition. Strategies for RF ablation concerning optimal electrode type and ablation technique were discussed at an RF ablation team meeting and were based on matching pre-procedural imaging findings with the results of planning US before each treatment. Our therapeutic goal for RF ablation was to achieve an ablative margin of at least $0.5 \mathrm{~cm}$ in the normal liver tissue surrounding the tumor, with the exception of subcapsular and perivascular tumors [25]. Procedures were finished when the hyperechoic ablation zone on the US was large enough to cover the entire tumor and the expected ablative margin. For assessment of technical success of the ablation procedure and immediate complications, CT was performed immediately after $\mathrm{RF}$ ablation. We followed proposed standardization of terminology and reporting criteria for image-guided tumor ablation throughout the manuscript [26].

\section{Follow-up after RF ablation}

All patients underwent contrast material-enhanced multiphase CT (arterial, portal, and delayed phases) with or without magnetic resonance imaging (MRI) and laboratory tests including tumor marker for assessment of therapeutic outcomes after RF ablation. Tests were performed at 1 month after initial treatment, every 3 months during the first two years after RF ablation, and every 4-6 months thereafter with visits to the outpatient clinic as part of our follow-up protocol. If extrahepatic recurrence (ER) was clinically suspected or unexplained elevation of tumor marker was observed, chest CT, brain MRI, and whole body bone scintigraphy with or without positron emission tomography-CT were performed. If recurrent tumor was identified during the follow-up period, patients were treated with RF ablation, transarterial chemoembolization, sorafenib, radiation therapy, or conservative treatment, based on the results of a multidisciplinary discussion for HCC treatment that depended on the characteristics of the tumor recurrence, liver function, and the general condition of the patient. Tumor recurrence after initial RF ablation was classified into three subtypes according to the reporting guidelines [26]: LTP, intrahepatic distant recurrence (IDR), and ER. In our study, IDR and ER were defined as tumor recurrence, whereas LTP was excluded because our aim was to investigate the role of antiviral treatment on $\mathrm{HCC}$ recurrence after RF ablation.

\section{Statistical analysis}

Categorical variables are described as frequencies and percentages. Continuous variables are presented as mean \pm standard deviation (SD) and median with interquartile range for parametric and non-parametric variables, respectively. The probabilities of tumor recurrence and overall survival were assessed according to the use of antiviral treatment. The full cohort consisted of 125 patients who received antiviral treatment and 103 patients who did not. We used a 1-to-n propensity score matching from a logistic regression to minimize the difference in baseline covariates between two groups. We performed propensity score matching in consideration of all variables in Table 1 (age, gender, tumor size, platelet count, prothrombin time, albumin, total bilirubin, AST, ALT, $\log _{10}$ HBV DNA, AFP, HBeAg status, LC, and Child-Pugh class). Propensity score matching was done using the caliper matching, and the caliper width was 0.2 of the standard deviation of the logit of the propensity score. To assess the balance of variables used matching, standardized mean difference was checked. A value $<0.10$ indicates a very small difference, $0.1-0.3$ indicates a small difference, $0.3-0.5$ indicates a moderate difference, and $>0.5$ indicates a large difference [27]. The matched cohort consisted of 103 patients from the antiviral treatment group and 62 from the non-antiviral treatment group. Kaplan-Meier curves of the two patient groups were used to estimate time to recurrence and overall survival, and were compared using a log-rank test and a weighted log-rank test for the full cohort and the matched cohort, respectively. The follow-up duration for survival analysis was defined as the interval between the first RF ablation and either the incidence of event or the last visit to the outpatient clinic before August 31, 2014. Univariable and multivariable Cox proportional hazards models were used to assess the risk factors for tumor recurrence and overall survival after RF ablation in the full cohort. The variables used for multivariable analysis were selected on the basis of statistical significance in the univariable analysis $(p<0.20)$ or clinical significance. Multivariable analysis was performed using a forward conditional stepwise procedure to avoid multicollinearity. A $p$-value less than 0.05 in a 2 -sided test is regarded as statistically significant. These analyses were conducted using SAS version 9.4 (SAS Institute, Cary, NC) and R 2.10.0 (Vienna, Austria; http://www.R-project.org).

\section{What is current knowledge}

Recent studies show that the use of oral antiviral treatment improves clinical outcomes in patients with chronic hepatitis B. In particular, oral antiviral treatment has a favorable outcome on the prevention of hepatitis $\mathrm{B}$ virus (HBV)-related hepatocellular carcinoma (HCC). Oral antiviral treatment results in favorable outcomes in terms of tumor recurrence and overall survival of HBVrelated $\mathrm{HCC}$ after surgical resection.

\section{What is new here}

Oral antiviral treatment reduces tumor recurrence and improves overall survival in patients with HBV-related HCC after radiofrequency (RF) ablation. Virological 
suppression by antiviral treatment is important for the prognosis of $\mathrm{HCC}$ patients with chronic hepatitis B after RF ablation.

\section{Abbreviations}

$\mathrm{HCC}$, hepatocellular carcinoma; RF, radiofrequency; $\mathrm{HBV}$, hepatitis B virus; CHB, chronic hepatitis B; HBsAg, hepatitis $B$ virus surface antigen; $\mathrm{HBe} A g$, hepatitis $B$ virus envelope antigen; nucleos(t)ide, nucleoside/nucleotide; $\mathrm{CT}$, computed tomography; prothrombin time-international normalized ratio, PT-INR; AST, aspartate transaminase; ALT, alanine transaminase; AFP, alpha-fetoprotein; US, ultrasonography; MRI, magnetic resonance imaging; LTP, local tumor progression; IDR, intrahepatic distant recurrence; ER, extrahepatic recurrence; SD, standard deviation; $\mathrm{CI}$, confidence interval.

\section{CONFLICTS OF INTEREST}

None of the authors have any conflicts of interest to declare.

\section{Authors' contributions}

Dr. Sohn, Dr. Kang, Dr. Rhim, and Dr. Y-H Paik have full access to all of the data in the study and take responsibility for the integrity of the data and the accuracy of the data analysis. Study concept and design: Sohn, Kang, Cho, Rhim, Y-H Paik, Jung. Acquisition of data: Sohn, Kang. Analysis and interpretation of data: Sohn, Kang, Rhim, Y-H Paik, Cho. Drafting of the manuscript: Sohn, Kang, Rhim, Y-H Paik. Critical revision of the manuscript for important intellectual content: MW Lee, Lim, Sinn, Gwak, MS Choi, JH Lee, Koh, SW Paik, Shim. Statistical analysis: Sohn, SK Choi, Jung, Y-H Paik.

\section{REFERENCES}

1. Jemal A, Bray F, Center MM, Ferlay J, Ward E, Forman D. Global cancer statistics. CA Cancer J Clin. 2011; 61:69-90.

2. European Association For The Study Of The L, European Organisation For R and Treatment Of C. EASL-EORTC clinical practice guidelines: management of hepatocellular carcinoma. Journal of hepatology. 2012; 56:908-943.

3. Forner A, Llovet JM, Bruix J. Hepatocellular carcinoma. Lancet. 2012; 379:1245-1255.

4. Komorizono Y, Oketani M, Sako K, Yamasaki N, Shibatou T, Maeda M, Kohara K, Shigenobu S, Ishibashi K, Arima T. Risk factors for local recurrence of small hepatocellular carcinoma tumors after a single session, single application of percutaneous radiofrequency ablation. Cancer. 2003; 97:1253-1262.
5. N'Kontchou G, Mahamoudi A, Aout M, Ganne-Carrie N, Grando V, Coderc E, Vicaut E, Trinchet JC, Sellier N, Beaugrand M, Seror O. Radiofrequency ablation of hepatocellular carcinoma: long-term results and prognostic factors in 235 Western patients with cirrhosis. Hepatology. 2009; 50:1475-1483.

6. Yang B, Zou J, Xia J, Ren Z, Gan Y, Wang Y, Zhang B, Ge N, Wang D, Chen Y, Chen R, Li L, Ye S, Wang X. Risk factors for recurrence of small hepatocellular carcinoma after long-term follow-up of percutaneous radiofrequency ablation. European journal of radiology. 2011; 79:196-200.

7. Facciorusso A, Del Prete V, Antonino $M$, Neve V, Crucinio N, Di Leo A, Carr BI, Barone M. Serum ferritin as a new prognostic factor in hepatocellular carcinoma patients treated with radiofrequency ablation. Journal of gastroenterology and hepatology. 2014; 29:1905-1910.

8. Hung IF, Poon RT, Lai CL, Fung J, Fan ST, Yuen MF. Recurrence of hepatitis B-related hepatocellular carcinoma is associated with high viral load at the time of resection. The American journal of gastroenterology. 2008; 103:1663-1673.

9. Qu LS, Jin F, Huang XW, Shen XZ. High hepatitis B viral load predicts recurrence of small hepatocellular carcinoma after curative resection. Journal of gastrointestinal surgery. 2010; 14:1111-1120.

10. Sohn W, Paik YH, Kim JM, Kwon CH, Joh JW, Cho JY, Gwak GY, Choi MS, Lee JH, Koh KC, Paik SW, Yoo BC. HBV DNA and HBsAg levels as risk predictors of early and late recurrence after curative resection of HBV-related hepatocellular carcinoma. Annals of surgical oncology. 2014; 21:2429-2435.

11. Sohn W, Paik YH, Lee MW, Rhim H, Lim HK, Cho JY, Gwak GY, Choi MS, Lee JH, Koh KC, Paik SW, Yoo BC. Predisposing factors for recurrence of HBV-related small hepatocellular carcinoma after percutaneous radiofrequency ablation. Scandinavian journal of gastroenterology. 2014; 49:373-380.

12. Wu CY, Chen YJ, Ho HJ, Hsu YC, Kuo KN, Wu MS, Lin JT. Association between nucleoside analogues and risk of hepatitis B virus-related hepatocellular carcinoma recurrence following liver resection. Jama. 2012; 308:1906-1914.

13. Yin J, Li N, Han Y, Xue J, Deng Y, Shi J, Guo W, Zhang H, Wang H, Cheng S, Cao G. Effect of antiviral treatment with nucleotide/nucleoside analogs on postoperative prognosis of hepatitis B virus-related hepatocellular carcinoma: a two-stage longitudinal clinical study. Journal of clinical oncology. 2013; 31:3647-3655.

14. Huang G, Lau WY, Wang ZG, Pan ZY, Yuan SX, Shen F, Zhou WP, Wu MC. Antiviral therapy improves postoperative survival in patients with hepatocellular carcinoma: a randomized controlled trial. Annals of surgery. 2015; 261:56-66. 
15. Kim YS, Lim HK, Rhim H, Lee MW, Choi D, Lee WJ, Paik SW, Koh KC, Lee JH, Choi MS, Gwak GY, Yoo BC. Ten-year outcomes of percutaneous radiofrequency ablation as first-line therapy of early hepatocellular carcinoma: analysis of prognostic factors. Journal of hepatology. 2013; 58:89-97.

16. Lee TY, Lin JT, Zeng YS, Chen YJ, Wu MS, Wu CY. Association between nucleos(t)ide analog and tumor recurrence in hepatitis B virus-related hepatocellular carcinoma after radiofrequency ablation. Hepatology. 2016; 63:1517-1527.

17. Kang TW, Lee MW, Hye MJ, Song KD, Lim S, Rhim H, Lim HK, Cha DI. Percutaneous radiofrequency ablation of hepatic tumours: Factors affecting technical failure of artificial ascites formation using an angiosheath. Clinical radiology. 2014; 69:1249-1258.

18. Kim YS, Lee WJ, Rhim H, Lim HK, Choi D, Lee JY. The minimal ablative margin of radiofrequency ablation of hepatocellular carcinoma $(>2$ and $<5 \mathrm{~cm}$ ) needed to prevent local tumor progression: 3D quantitative assessment using CT image fusion. AJR American journal of roentgenology. 2010; 195:758-765.

19. Bruix J, Sherman M. Management of hepatocellular carcinoma. Hepatology. 2005; 42:1208-1236.

20. Korean Association for the Study of the L. KASL Clinical Practice Guidelines: Management of chronic hepatitis B. Clinical and molecular hepatology. 2012; 18:109-162.

21. Korean Association for the Study of the L. KASL clinical practice guidelines: management of chronic hepatitis B. Clinical and molecular hepatology. 2016; 22:18-75.

22. Berzigotti A, Castera L. Update on ultrasound imaging of liver fibrosis. Journal of hepatology. 2013; 59:180-182.

23. Rhim H, Choi D, Kim YS, Lim HK, Choe BK. Ultrasonography-guided percutaneous radiofrequency ablation of hepatocellular carcinomas: a feasibility scoring system for planning sonography. European journal of radiology. 2010; 75:253-258.

24. Kang TW, Lim HK, Lee MW, Kim YS, Choi D, Rhim H. Perivascular versus nonperivascular small HCC treated with percutaneous RF ablation: retrospective comparison of long-term therapeutic outcomes. Radiology. 2014; 270:888-899.

25. Kang TW, Kim JM, Rhim H, Lee MW, Kim YS, Lim HK, Choi D, Song KD, Kwon CH, Joh JW, Paik SW, Paik YH, Ahn JH. Small Hepatocellular Carcinoma: Radiofrequency Ablation versus Nonanatomic Resection--Propensity Score Analyses of Long-term Outcomes. Radiology. 2015; 275:908-919.

26. Ahmed M, Solbiati L, Brace CL, Breen DJ, Callstrom MR, Charboneau JW, Chen MH, Choi BI, de Baere T, Dodd GD, 3rd, Dupuy DE, Gervais DA, Gianfelice D, Gillams AR, Lee FT, Jr., Leen E, et al. Image-guided tumor ablation: standardization of terminology and reporting criteria--a 10-year update. Radiology. 2014; 273:241-260.

27. Burnand B, Kernan WN, Feinstein AR. Indexes and boundaries for "quantitative significance" in statistical decisions. Journal of clinical epidemiology. 1990; 43:1273-1284.

28. El-Serag HB. Epidemiology of viral hepatitis and hepatocellular carcinoma. Gastroenterology. 2012; 142:1264-1273 e1261.

29. Yang T, Lu JH, Zhai J, Lin C, Yang GS, Zhao RH, Shen F, Wu MC. High viral load is associated with poor overall and recurrence-free survival of hepatitis B virusrelated hepatocellular carcinoma after curative resection: a prospective cohort study. European journal of surgical oncology. 2012; 38:683-691.

30. Liaw YF, Sung JJ, Chow WC, Farrell G, Lee CZ, Yuen H, Tanwandee T, Tao QM, Shue K, Keene ON, Dixon JS, Gray DF, Sabbat J and Cirrhosis Asian Lamivudine Multicentre Study G. Lamivudine for patients with chronic hepatitis B and advanced liver disease. The New England journal of medicine. 2004; 351:1521-1531.

31. Hosaka T, Suzuki F, Kobayashi M, Seko Y, Kawamura Y, Sezaki H, Akuta N, Suzuki Y, Saitoh S, Arase Y, Ikeda K, Kobayashi M, Kumada H. Long-term entecavir treatment reduces hepatocellular carcinoma incidence in patients with hepatitis B virus infection. Hepatology. 2013; 58:98-107.

32. Chang TT, Liaw YF, Wu SS, Schiff E, Han KH, Lai CL, Safadi R, Lee SS, Halota W, Goodman Z, Chi YC, Zhang H, Hindes R, Iloeje U, Beebe S, Kreter B. Long-term entecavir therapy results in the reversal of fibrosis/cirrhosis and continued histological improvement in patients with chronic hepatitis B. Hepatology. 2010; 52:886-893.

33. Marcellin P, Gane E, Buti M, Afdhal N, Sievert W, Jacobson IM, Washington MK, Germanidis G, Flaherty JF, Schall RA, Bornstein JD, Kitrinos KM, Subramanian GM, McHutchison JG, Heathcote EJ. Regression of cirrhosis during treatment with tenofovir disoproxil fumarate for chronic hepatitis B: a 5-year open-label follow-up study. Lancet. 2013; 381:468-475.

34. Shiina S, Tateishi R, Arano T, Uchino K, Enooku K, Nakagawa H, Asaoka Y, Sato T, Masuzaki R, Kondo Y, Goto T, Yoshida H, Omata M, Koike K. Radiofrequency ablation for hepatocellular carcinoma: 10-year outcome and prognostic factors. The American journal of gastroenterology. 2012; 107:569-577.

35. Lok AS, McMahon BJ. Chronic hepatitis B. Hepatology. 2007; 45:507-539.

36. Liaw YF, Leung N, Kao JH, Piratvisuth T, Gane E, Han KH, Guan R, Lau GK, Locarnini S and Chronic Hepatitis BGWPotA-PAftSotL. Asian-Pacific consensus statement on the management of chronic hepatitis B: a 2008 update. Hepatology international. 2008; 2:263-283. 
37. European Association For The Study Of The L. EASL clinical practice guidelines: Management of chronic hepatitis B virus infection. Journal of hepatology. 2012; 57:167-185.

38. Sinn DH, Lee J, Goo J, Kim K, Gwak GY, Paik YH, Choi MS, Lee JH, Koh KC, Yoo BC, Paik SW. Hepatocellular carcinoma risk in chronic hepatitis B virus-infected compensated cirrhosis patients with low viral load. Hepatology. 2015; 62:694-701.

39. Bruix J, Sherman M and American Association for the Study of Liver D. Management of hepatocellular carcinoma: an update. Hepatology. 2011; 53:1020-1022. 